\title{
MECHANICAL PROPERTIES OF FORGED TUNGSTEN HEAVY ALLOYS
}

\author{
OndŘej KováŘíK ${ }^{a, *}$, JAROSlav ČEeH ${ }^{a}$, JiŘí ČAPEK ${ }^{a}$, MiChal HaJíčEK $^{b}$, \\ JAKUB KLEČKA ${ }^{a, c}$, JAN SiEGL ${ }^{a}$ \\ ${ }^{a}$ Czech Technical University in Prague, Faculty of Nuclear Sciences and Physical Engineering, Department of \\ Materials, Trojanova 13, Praha 2, Czech Republic \\ ${ }^{b}$ UJP Praha a.s., Nad Kamínkou 1345, Praha-Zbraslav, Czech Republic \\ ${ }^{c}$ Czech Academy of Sciences, Institute of Plasma Physics, Za Slovankou 1782/3, Praha-Libeř, Czech Republic \\ * corresponding author: ondrej.kovarik@fjfi.cvut.cz
}

\begin{abstract}
Tungsten heavy alloys are composite materials containing spherical tungsten particles embedded in binder matrix. Their excellent mechanical properties can be further improved by rotary forging. This paper aims to gain deeper understanding of the forging process by investigating the local elastic modulus, hardness, and residual stress of individual phases in W6Ni3Co pseudo-alloy. The resulting global properties of the composite material such as stress-strain behavior, fracture toughness and fatigue crack growth rate behavior are also studied. The results show that sintered and quenched material consists of highly textured matrix containing nearly perfect single crystal spheres of pure $\mathrm{W}$. The rotary forging leads to significant lattice deformations destroying the texture and significantly increasing the hardness of both $\mathrm{WNiCo}$ matrix and $\mathrm{W}$ particles and making residual stresses in $\mathrm{W}$ particles anisotropic with increased compression along the longitudinal axis of the forged part.
\end{abstract}

KEYWORDS: Instrumented indentation, residual strain, stress-strain, tungsten heavy alloy, W6Ni3Co.

\section{INTRODUCTION}

Tungsten heavy alloys (WHA) are two phase materials consisting of tungsten particles embedded in binder matrix typically consisting of $\mathrm{W}-\mathrm{Ni}-\mathrm{Cu}, \mathrm{W}-\mathrm{Ni}-\mathrm{Fe}, \mathrm{W}-$ $\mathrm{Ni}-\mathrm{Co}$ or W-Ni-Fe-Co. These materials feature good wear resistance and high strength, density, thermal conductivity, corrosion resistance and radiation absorption. These properties determine the use of WHAs for counterweights, kinetic penetrators, electrical contacts, radiation shielding etc. The high temperature application of WHA's is limited by the melting point of $\mathrm{Ni}$ rich binder which lies above $1400{ }^{\circ} \mathrm{C}$. Despite this limitation, WHA's are considered as candidate materials for first wall of future fusion devices [1, 2]. The mechanical properties of WHA's can be compared to pure tungsten. However the fracture toughness of WHA's at room temperature can be approximately one order of magnitude higher than pure W $\underline{3}$. Moreover the mechanical properties of WHA's can be further improved by thermomechanical treatment such as rotary forging [4, 5].

This paper summarizes global or macroscopic engineering properties of the $\mathrm{W} 6 \mathrm{Ni3Co}$ tungsten heavy alloy in as sintered and quenched (SQ) and forged and annealed (FA) states. The observed changes are related to the local changes of the residual stress distribution, microhardness and elastic modulus of individual phases of the WHA, i.e. of the $\mathrm{Ni}$ rich matrix and $\mathrm{W}$ particles.

\section{EXPERIMENTAL}

The W6Ni3Co alloy was prepared from powder mixture by cold isostatic pressing, sintering at $1530{ }^{\circ} \mathrm{C}$, annealing and quenching. The sintered and quenched specimens were designated SQ and had cylindrical shape with diameter of $11.5 \mathrm{~mm}$ and length of 120 $\mathrm{mm}$. Additional rotary forging and subsequent annealing was applied to specimens designated FA (final diameter of $9 \mathrm{~mm}$ and length $\approx 160 \mathrm{~mm}$ ). Small rectangular bar specimens of dimension $4 \times 3 \times 32 \mathrm{~mm}$ were cut using electric discharge machining and fine ground to final shape. This type of bar specimen was used for all performed measurements.

Stress-strain behavior was measured by the method of Herbert [6, 7]. The used four point bending fixture with outer span of $27 \mathrm{~mm}$ and inner span of $13.5 \mathrm{~mm}$ is in figure 1 The measurement evaluates the stress strain curve from the records of loading force and strains on compression and tensile surfaces of the specimen (see strain gages SC and ST in figure 1) and is limited by the $5 \%$ strain. In order to avoid tedious strain gaging work, the strains were measured using digital image correlation (DIC) with help of the ncorr software [8. The stress-strain curves in uniaxial tension were also measured for the investigated materials and evaluated according to standard ISO 6892-1 [9].

Fracture toughness was measured using the Jintegral approach according to ASTM standard E1820 [10. The J-integral characterizes the energy release by rate of the growing crack, i.e. the amount of elastic energy released by crack grown by unit area. 

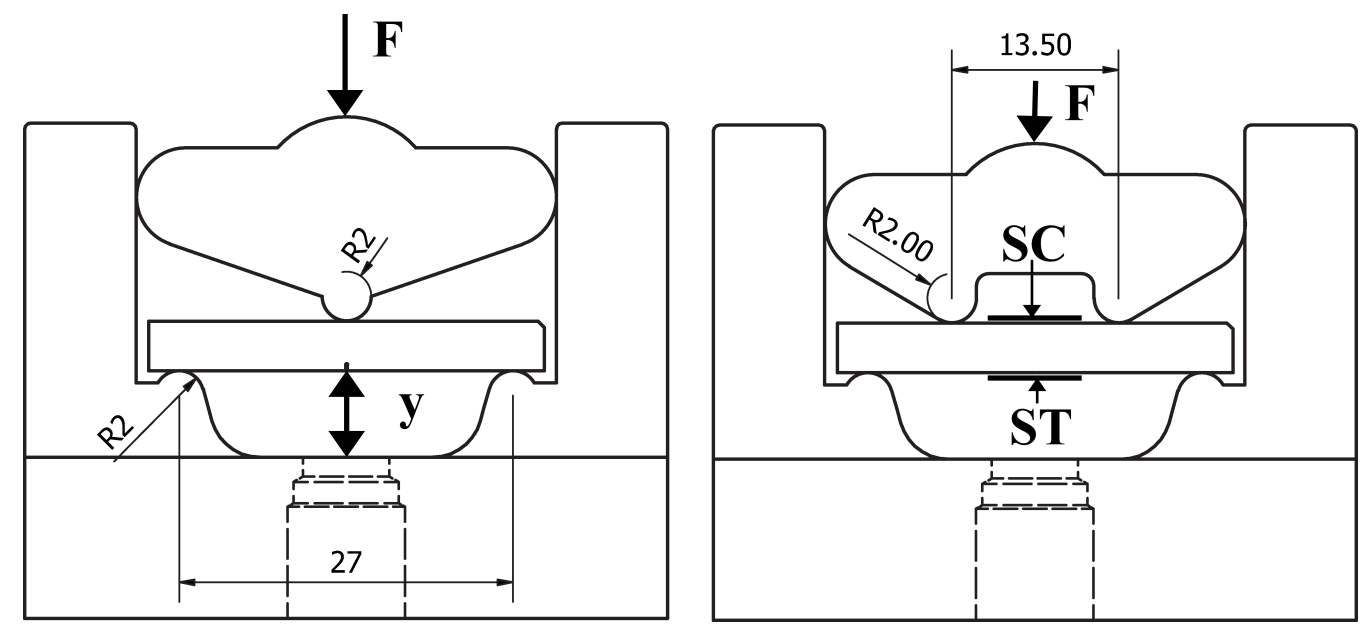

Figure 1. The schematic drawing of the three point bending setup used for fracture toughness measurement and four point bending setup used for stress-strain curve measurement. The loadline displacement $\mathbf{y}$ and compressive strain $\mathbf{S C}$ at the top face and tensile strain $\mathbf{S T}$ at the bottom face of the specimens are marked.

\begin{tabular}{llccccc}
\hline temper & sample & $\begin{array}{c}E_{t} \\
(\mathrm{GPa})\end{array}$ & $\begin{array}{c}E_{c} \\
(\mathrm{GPa})\end{array}$ & $\begin{array}{c}R_{p} 0.2_{, t} \\
(\mathrm{MPa})\end{array}$ & $\begin{array}{c}R_{p} 0.2_{, c} \\
(\mathrm{MPa})\end{array}$ & $\begin{array}{c}R_{m, t} \\
(\mathrm{MPa})\end{array}$ \\
\hline SQ & AD1 & 307 & 285 & 685 & 690 & $\geq 960$ \\
SQ & AD13 & 304 & 258 & 683 & 701 & $\geq 973$ \\
FA & AE1 & 313 & 393 & 1617 & 1546 & $\geq 1701$ \\
FA & AE13 & 329 & 357 & 1574 & 1505 & $\geq 1673$ \\
\hline
\end{tabular}

TABLE 1. Mechanical properties of individual specimens obtained by four point bending. Subscripts $\mathrm{c}$ and $\mathrm{t}$ denote tension and compression respectively.
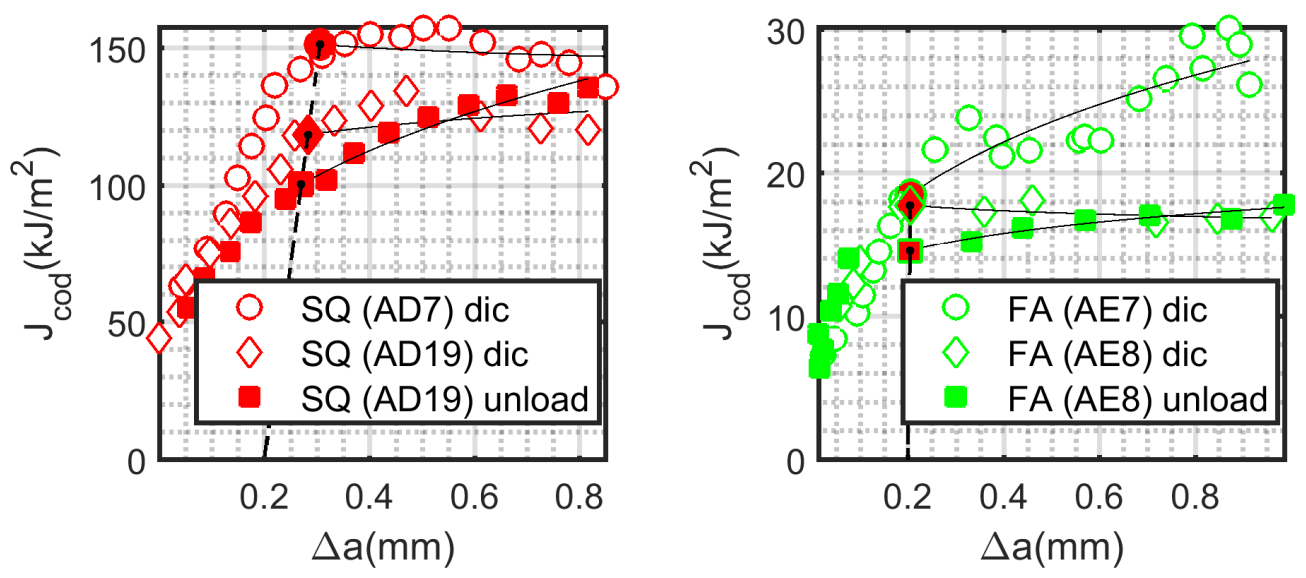

Figure 2. R-curves of sintered and quenched (SQ) and forged and annealed specimens (FA). The construction lines intersecting the mesured curve at $J_{I c}$ are marked. The crack length is measured by DIC or from unloading compliance.

\begin{tabular}{ccccccccc}
\hline temper & $\begin{array}{c}R_{p} 0.2, u \\
(\mathrm{MPa})\end{array}$ & $\begin{array}{c}R_{m, u} \\
(\mathrm{MPa})\end{array}$ & $\begin{array}{c}A \\
(\%)\end{array}$ & $\begin{array}{c}E_{t} \\
(\mathrm{GPa})\end{array}$ & $\begin{array}{c}R_{p} 0.2_{, t} \\
(\mathrm{MPa})\end{array}$ & $\begin{array}{c}R_{p} 0.2_{, c} \\
(\mathrm{MPa})\end{array}$ & $\begin{array}{c}K_{I C} \\
(\mathrm{MPa} \sqrt{\mathrm{m}})\end{array}$ & $\begin{array}{c}\Delta K_{t h} \\
(\mathrm{MPa} \sqrt{\mathrm{m}})\end{array}$ \\
\hline SQ & 630 & 1005 & 26.7 & 306 & 683 & 695 & 172 & 28 \\
FA & 1630 & 1627 & 7.3 & 321 & 1569 & 1525 & 65 & 50 \\
\hline
\end{tabular}

TABLE 2. Average values of global properties. Mechanical properties obtained by the uniaxial test are denoted by subscript $\mathrm{u}$, subscript $\mathrm{t}$ and $\mathrm{c}$ denote properties in tension and compression obtained from four point bending test. 


\begin{tabular}{|c|c|c|c|c|c|c|c|}
\hline temper & phase & $\begin{array}{l}H_{I T, l} \\
(\mathrm{GPa})\end{array}$ & $\begin{array}{l}H_{I T, g} \\
(\mathrm{GPa})\end{array}$ & $\begin{array}{c}E_{I T, l} \\
(\mathrm{GPa})\end{array}$ & $\begin{array}{c}E_{I T, g} \\
(\mathrm{GPa})\end{array}$ & $\begin{array}{c}\varepsilon_{l} \\
\left(10^{-3}\right)\end{array}$ & $\begin{array}{c}\varepsilon_{r o t} \\
\left(10^{-3}\right)\end{array}$ \\
\hline SQ & $\begin{array}{l}\mathrm{W} \\
\mathrm{Ni}\end{array}$ & $\begin{array}{l}7.5 \pm 0.5 \\
6.8 \pm 0.3\end{array}$ & $4.3 \pm 0.15$ & $\begin{array}{l}412 \pm 19 \\
296 \pm 14\end{array}$ & $299 \pm 20$ & $-1.0 \pm 0.3$ & $\begin{array}{l}-1.0 \pm 0.1 \\
-2.1 \pm 0.3^{*}\end{array}$ \\
\hline FA & $\begin{array}{l}\mathrm{W} \\
\mathrm{Ni}\end{array}$ & $\begin{array}{l}8.9 \pm 0.5 \\
7.8 \pm 0.4\end{array}$ & $6.8 \pm 0.25$ & $\begin{array}{l}404 \pm 17 \\
311 \pm 37\end{array}$ & $275 \pm 24$ & $\begin{array}{r}-1.3 \pm 0.2 \\
2.1 \pm 0.9\end{array}$ & $\begin{array}{r}-0.9 \pm 0.2 \\
0.6 \pm 0.2\end{array}$ \\
\hline
\end{tabular}

TABLE 3. Local properties of $\mathrm{W}$ particles and Ni matrix of two investigated material tempers: instrumented nanohardness $H_{I T}$, indentation modulus $E_{I T}$, longitudinal and isotropic residual strains $\varepsilon_{l}, \varepsilon_{\text {rot }}$ in W particles and $\mathrm{Ni}$ rich matrix. * indicates possible measurement artifact.

The specimen with fatigue precrack of nominal length $2 \mathrm{~mm}$ was loaded in three point bending (see figure 1). The loadline displacement $y$ was measured using an LVDT sensor, crack opening displacement (COD) was evaluated from DIC. The crack length was measured using DIC by the method described in [11] and also using unloading compliance.

The fatigue crack growth rate was measured in resonance bending using the method described in [12]. The nominal stress ratio was $R=-1$. The crack initiated from a straight notch machined using a slow speed diamond saw. The nominal notch length was $0.5 \mathrm{~mm}$, its width was about $0.15 \mathrm{~mm}$. The test was performed in so called rate controlled mode. In this mode, the crack growth rate is controlled by a closed loop technique and the setpoint is prescribed by an exponential function $\frac{d a}{d N}=\left.\frac{d a}{d N}\right|_{0} e^{C\left(a-a_{0}\right)}$. This approach eliminates possible crack arrests that can experienced using standard load shedding procedures, at the same time, the duration of the experiment is known in advance. The fatigue crack growth rate experiment consisted of two parts. In the load shedding part, the crack growth rate was decreased from $\frac{d a}{d N}=10^{-9} \mathrm{~m} /$ cycle to $\frac{d a}{d N}=10^{-12} \mathrm{~m} /$ cycle at a crack length of $a=1.1 \mathrm{~mm}$. In the following load increase part, the crack growth rate was increased up to $\frac{d a}{d N}=10^{-6} \mathrm{~m} /$ cycle at $a=2.4 \mathrm{~mm}$.

Nanoindentation was carried out on NHT tester (Anton Paar, Graz, Austria) using Berkovich indenter. Indentations with partial unloadings to maximum load of $0.5 \mathrm{~N}$ were performed in order to study the evolution of mechanical properties with increasing penetration depth $h_{m}$. The acquired data (force-penetration depth dependency) were evaluated to obtain hardness $H_{I T}$ and Young's modulus $E_{I T}$ according to the ISO 14577 [13] standard by the Oliver-Pharr method [14. Poisson ratio $\nu=0.3$ was assumed during elastic modulus computation.

The X'Pert PRO MPD diffractometer (PANalytical, Malvern, United Kingdom) was used to measure lattice deformations of $\{220\}$ and $\{311\}$ planes of the $\mathrm{W}$ and Ni phase, respectively, using the manganese radiation. To determine residual strain, the $\sin ^{2} \Psi$ method was used. The irradiated area was specified by pinhole of the size of $2 \mathrm{x} 1 \mathrm{~mm}^{2}$. The residual strains were measured in longitudinal direction, however, such measurement was unsuccessful in the matrix due to its heavy texture. Therefore the measurements were also performed with sample rotating around the axis perpendicular to the measured surface in order to characterize the 'hydrostatic' strain. Such measurement is, however, unsuitable for the measurement of other than 'hydrostatic' types of strain.

Microstructure of metalographically polished samples was observed in electron channeling contrast mode using high resolution scanning electron microscope JEOL JSM-IT500 HR (JEOL, Tokyo, Japan). The final polishing was performed in colloidal silica using the Vibromet vibratory polisher (Buehler, Lake Bluff, IL, USA).

\section{Results}

\subsection{Global properties}

The results of stress-strain measurements are presented in figure 3 The mechanical properties obtained from these curves are summarized in table 1 and average values are in table 2 2 The rotary forging increased the yield strength $R_{p} 0.2$ nearly 2.6 times. This increase of yield strength was accompanied by nearly fourfold reduction of ductility $A$.

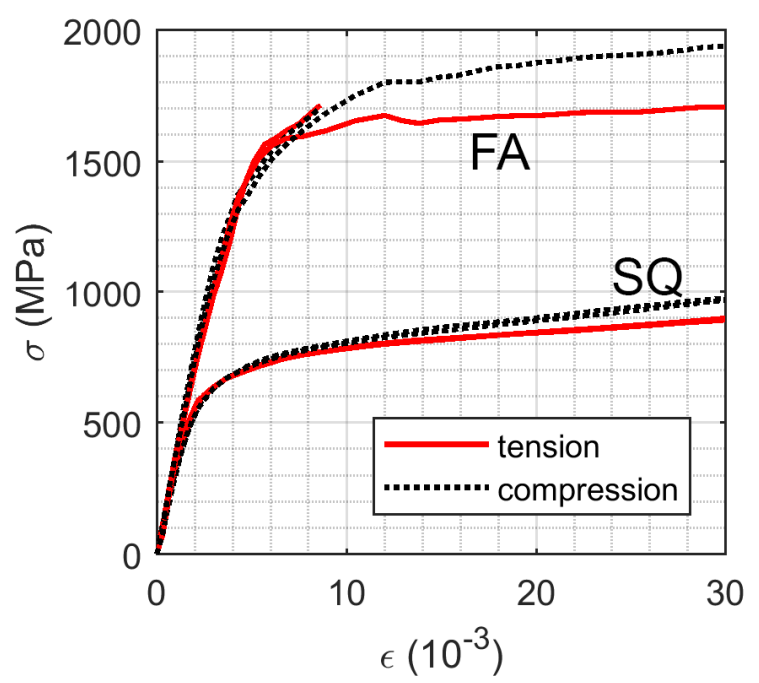

FiguRE 3. Stress-strain curves in tension and compression obtained from four point bending.

The R-curves describing the J-integral $J$ as a function of crack extension $\Delta a$ are shown in figure 2 Two 


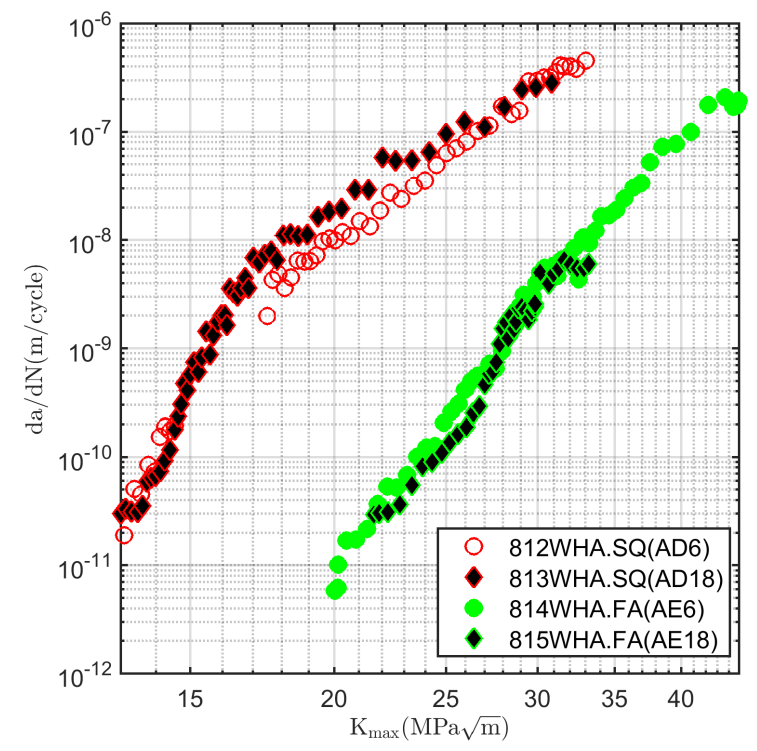

Figure 4. Crack growth rates $\frac{d a}{d N}$ vs. the maximum stress intensity factor $K_{\max }$ for sintered and quenched (SQ) and forged and annealed (FA) specimens.

specimens of each type were investigated. One specimen was tested without unloading with crack length measured only by DIC. The second specimen was tested with periodical unloading and crack length was estimated from both unloading slope and also by DIC. The R-curves show rising behavior up to the $J_{I C}$ value marked by the construction line in figure2 For higher crack extensions the $\mathrm{R}$ curve is relatively flat indicating the presence of brittle fracture mechanism. The resulting values of fracture toughness are summarized in table 2 The increased yield strength of rotary forged specimens was connected with nearly reciprocal decrease of fracture toughness $K_{I C}$. It should be noted, that the measured fracture toughness is significantly higher than that for pure tungsten which is $\approx 5 \mathrm{MPa} \sqrt{\mathrm{m}}$ at room temperature [15].

The fatigue crack growth rate $\frac{d a}{d N}$ as a function of the maximum stress intensity factor $K_{\max }$ is plotted in figure 4. The threshold values $\Delta K_{t h}$ defined at crack growth rate $\frac{d a}{d N}=10^{-10} \mathrm{~m} /$ cycle are presented in table 2 .

\subsection{Local Properties}

In order to explain the effect of rotary forging on global properties of the material, the local role of the $\mathrm{W}$ particles and Ni-rich matrix was studied by instrumented indentation and X-ray diffraction measurement.

The results of instrumented indentation are included in figures 5 and 6 . The indents were placed in centers of $\mathrm{W}$ particles and in the centers of Ni matrix regions. Despite the relatively low applied loads and high stiffness of the material, the volume characterized by the indentation may reach out of the phase of interest at higher load. At low loads, however the measured hardness was influenced by the indentation size

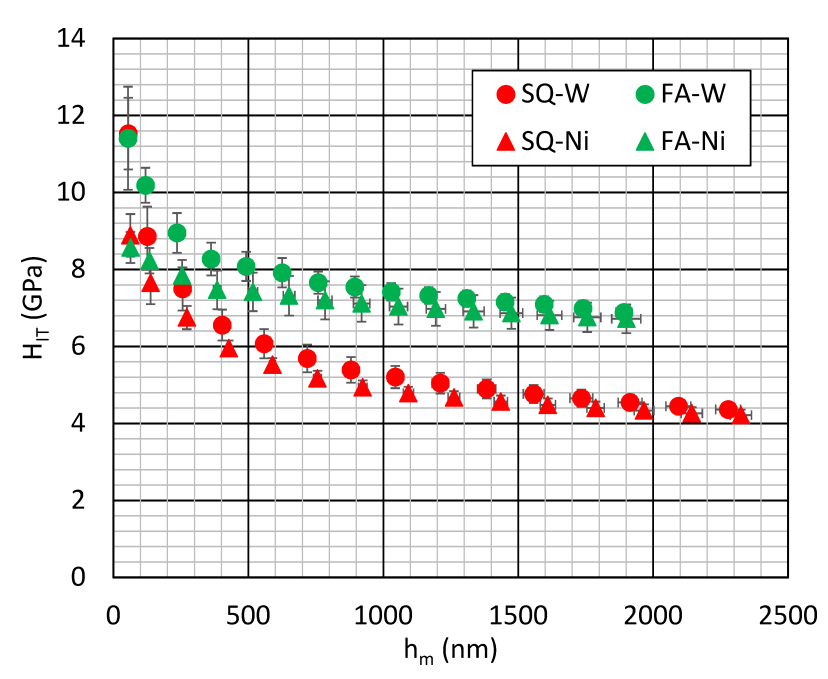

Figure 5. Hardness of $\mathrm{W}$ particles and Ni matrix determined by instrumented indentation by Berkovich indentor for different penetration depths $h_{m}$.

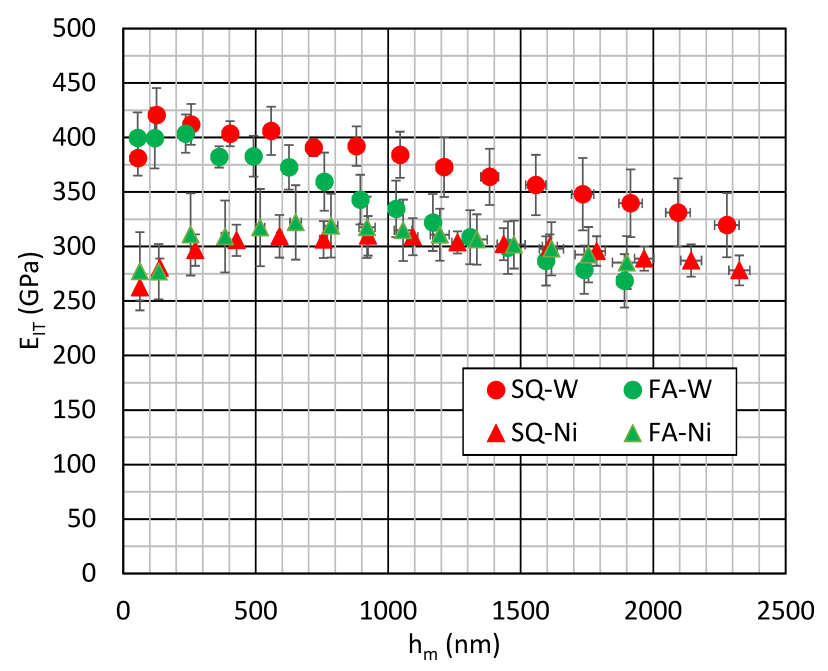

FiguRE 6. Elastic modulus of $\mathrm{W}$ particles and $\mathrm{Ni}$ matrix determined by instrumented indentation by Berkovich indentor for different penetration depths $h_{m}$.

effect [16]. The optimal load for characterization of local properties of each phase should be high enough to eliminate the indentation size effect on one hand. On the other hand, the load must be low enough to prevent the probed volume to reach out of the phase of interest. Analyzing figures 5 and 6 the indentation depth of about $250 \mathrm{~nm}$ appeared as suitable compromise and thus local individual phase properties $H_{I T, l}$, and $E_{I T, l}$ were estimated at this indentation depth. At maximum indentation depth, the measured values characterize the global macroscopic properties of the material $H_{I T, g}$ and $E_{I T, g}$. The representative values of both local and global indentation properties are summarized in table 3 The local hardness $H_{I T, l}$ of $\mathrm{W}$ particles is about $10 \%$ higher than the hardness of the Ni matrix, both values increase by $\approx 20 \%$ after rotary forging. Even higher increase of about $\approx 60 \%$ was observed for the global hardness. This indicates the 


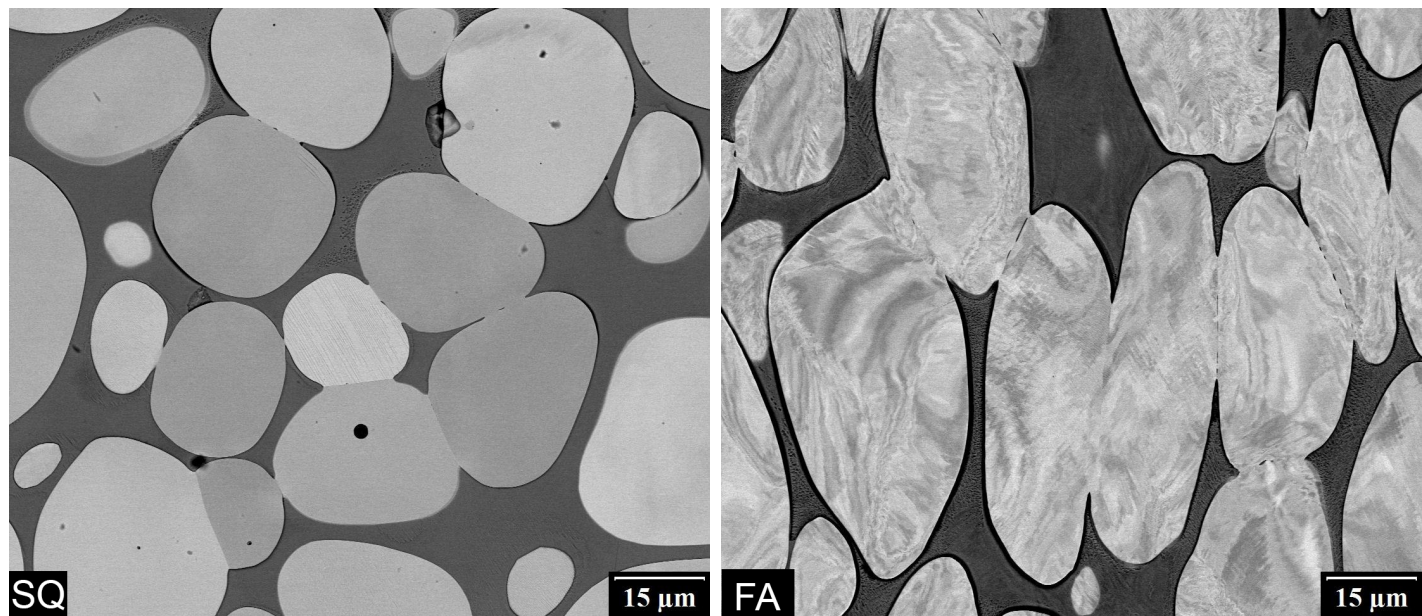

FIgURE 7. The influence of rotary forging on microstructure of $\mathrm{W}$ particles and Ni matrix observed using SEM in backscattered electron channeling contrast mode.

synergistic effect of W particle and Ni matrix hardness increase probably originating from the $\mathrm{W}-\mathrm{W}$ and W-Ni interfaces. Elastic modulus, on the other hand, shows no significant relation to the forging process neither at local or global scale. It was shown, that rotary forging influences $\mathrm{W}$ particles, $\mathrm{Ni}$ matrix and probably also well as the $\mathrm{W}-\mathrm{W}$ or $\mathrm{W}$-matrix interfaces.

The results of residual strain measurement by X-ray diffraction are summarized in table 3 Longitudinal strains $\varepsilon_{l}$ as well as isotropic strains $\varepsilon_{\text {rot }}$ obtained by rotating the specimen are included. Compressive strain is always indicated in W particles. For SQ specimens, the values of isotropic and longitudinal strains of W particles coincide, indicating 'hydrostatic' strain state. At the same time, the longitudinal strain in SQ Ni matrix could not be measured due to heavy texture. Under heavy texture, the performed measurement of isotropic strain results in a strain component of unknown orientation and thus should not be evaluated. After forging and annealing the compressive strains in $\mathrm{W}$ appear to get oriented as the isotropic strain $\varepsilon_{\text {rot }}$ is different from the longitudinal strain $\varepsilon_{l}$. Similar situation, i.e. oriented tension strain can be observed in Ni matrix of forged specimens. The above mentioned orientation of residual strains invokes higher longitudinal strain mismatch with increased compression of $\mathrm{W}$ particles by $\approx 0.6 \times 10^{-3}$ and corresponding increase in matrix tension by $\approx 1.5 \times 10^{-3}$ when comparing longitudinal strains $\varepsilon_{l}$ and isotropic averaged strains $\varepsilon_{\text {rot }}$. This increased stress mismatch can protect the inherently brittle $\mathrm{W}$ particles by imposing more compression on them up to the point of matrix yielding. This protection will be active at low loads, and together with the elimination of texture may cause the observed increase of fatigue performance of FA specimens (see figure 4). On the other hand, at high load, the matrix yields and the protection is decreased which can reduce fracture toughness (see figure 2 and table 2).

The texture changes observed by X-ray diffraction indicated that individual $\mathrm{W}$ grains had near perfect single crystal structures (however each particle was oriented differently) is SQ state. This structure was then heavily deformed during rotary forging. Similar effect was indicated in the Ni matrix, where the whole volume of the matrix had coherent crystal structure, that was later destroyed by forging. The described changes can clearly be observed on micrograph in figure 7

\section{Conclusion}

1. Stress-strain behavior, fracture toughness and fatigue crack growth rates of W6Ni3Co WHA in sintered and quenched (SQ) and forged and annealed (FA) state were measured. The following effects of rotary forging were observed:

$\triangleright$ significant increase of hardness, yield strength, tensile strength and fatigue performance.

$\triangleright$ significant decrease of ductility and fracture toughness

2. Hardness, elastic modulus and residual stress of $\mathrm{W}$ particles and Ni rich matrix were measured. The following effects of rotary forging were observed:

$\triangleright$ the increase of hardness of $\mathrm{W}$ particles and $\mathrm{Ni}$ matrix by $\approx 20 \%$ results in macroscopic hardness increase of $\approx 60 \%$.

$\triangleright$ increasing compressive strain in $\mathrm{W}$ particles in the longitudinal direction vas observed

The increased compressive strain in $\mathrm{W}$ may explain the increase of fatigue behavior at relatively low loads, whereas the hardening of individual phases results in decreased ductility and resulting decrease of fracture toughness. 


\section{LIST OF SYMBOLS}

$C O D$ crack opening displacement

$D I C$ digital image correlation

$R_{p} 0.2$ yield strength [MPa]

$R_{m}$ ultimate tensile strength [MPa]

$K_{I C}$ fracture toughness $[\mathrm{MPa} \sqrt{\mathrm{m}}]$

$J_{I C}$ critical value of J-integral $\left[\mathrm{kJ} / \mathrm{m}^{2}\right]$

$J_{\text {cod }} \mathrm{J}$-integral from COD $\left[\mathrm{kJ} / \mathrm{m}^{2}\right]$

$H_{I T}$ indentation hardness [GPa]

$E_{I T}$ indentation modulus [GPa]

$\varepsilon \quad$ strain $\left[10^{-3}\right]$

\section{ACKNOWLEDGEMENTS}

Financial support by Czech Science Foundation (project No. 19-14339S), Ministry of Industry and Trade (project No. FV10165) as well as the Grant Agency of the Czech Technical University in Prague (project No. SGS18/190/OHK4/3T/14) is gratefully acknowledged.

\section{REFERENCES}

[1] R. Neu, H. Maier, M. Balden, et al. Investigations on tungsten heavy alloys for use as plasma facing material. Fusion Engineering and Design 2017. DOI:10.1016/j.fusengdes.2017.01.043

[2] R. Neu, H. Maier, M. Balden, et al. Results on the use of tungsten heavy alloys in the divertor of ASDEX Upgrade. Journal of Nuclear Materials 2018. DOI:10.1016/j.jnucmat.2018.05.066

[3] D. Rittel, G. Weisbrod. Dynamic fracture of tungsten base heavy alloys. International Journal of Fracture 112(1):87-98, 2001. DOI:10.1023/A:1013581609836.

[4] R. Kocich, L. Kunčická, D. Dohnalík, et al. Cold rotary swaging of a tungsten heavy alloy: Numerical and experimental investigations. International Journal of Refractory Metals and Hard Materials 61:264-272, 2016. DOI:10.1016/J.IJRMHM.2016.10.005

[5] L. Kunčická, R. Kocich, C. Hervoches, A. Macháčková. Study of structure and residual stresses in cold rotary swaged tungsten heavy alloy. Materials Science and Engineering: A 704:25-31, 2017. DOI:10.1016/J.MSEA.2017.07.096

[6] H. Herbert. Ueber den Zusammenhang der Biegungselastizität des Gußeisens mit seiner Zug- und Druckelastizität. Forschungsarbeiten auf dem Gebiete des Ingenieurwesens pp. 39-81, 1910. DOI:10.1007/978-3-662-02218-4_2.
[7] R. A. Mayville, I. Finnie. Uniaxial stress-strain curves from a bending test. Experimental Mechanics 1982. DOI:10.1007/BF02326357

[8] J. Blaber, B. Adair, A. Antoniou. Ncorr: Open-Source 2D Digital Image Correlation Matlab Software. Experimental Mechanics 55(6):1105-1122, 2015. DOI:10.1007/s11340-015-0009-1.

[9] ISO. ISO6892-1: Metallic materials. Tensile testing. Method of test at room temperature. ISO 2016.

[10] ASTM. E1820: Standard Test Method for Measurement of Fracture Toughness. ASTM 2015. DOI:10.1520/E1820-15A.

[11] O. Kovářík, P. Haušild, J. Medřický, et al. Fatigue Crack Growth in Bodies with Thermally Sprayed Coating. Journal of Thermal Spray Technology 25(1-2):311-320, 2016. DOI:10.1007/s11666-015-0329-9.

[12] O. Kovarik, A. Materna, J. Siegl, et al. Fatigue Crack Growth in Plasma-Sprayed Refractory Materials. Journal of Thermal Spray Technology 28(1-2):87-97, 2019. DOI:10.1007/s11666-018-0790-3

[13] ISO. ISO14577: Metallic materials - Instrumented indentation test for hardness and material parameters. ISO 2015.

[14] W. Oliver, G. Pharr. An improved technique for determining hardness and elastic modulus using load and displacement sensing indentation experiments. Journal of Materials Research 7(6):1564-1583, 1992. DOI:10.1557/JMR.1992.1564

[15] B. Gludovatz, S. Wurster, A. Hoffmann, R. Pippan. Fracture toughness of polycrystalline tungsten alloys. International Journal of Refractory Metals and Hard Materials 28(6):674-678, 2010. DOI:10.1016/J.IJRMHM.2010.04.007

[16] W. D. Nix, H. Gao. Indentation size effects in crystalline materials: A law for strain gradient plasticity. Journal of the Mechanics and Physics of Solids 46(3):411425, 1998. DOI:10.1016/S0022-5096(97)00086-0. 